Voix et Images

volXetimages

\title{
Index du volume XXVIII
}

Volume 29, numéro 1 (85), automne 2003

\section{Claire Martin}

URI : https://id.erudit.org/iderudit/007550ar

DOI : https://doi.org/10.7202/007550ar

Aller au sommaire du numéro

\section{Éditeur(s)}

Université du Québec à Montréal

\section{ISSN}

0318-9201 (imprimé)

1705-933X (numérique)

Découvrir la revue

Citer ce document

(2003). Index du volume XXVIII. Voix et Images, 29(1), 171-172.

https://doi.org/10.7202/007550ar d'utilisation que vous pouvez consulter en ligne.

https://apropos.erudit.org/fr/usagers/politique-dutilisation/ 


\section{N D E X D U VOLUME XXVIII}

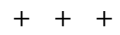

ALLARD, Jacques, «Pour relire Noël

Audet», 1, p. 45-59.

ARSENAULT, Solange, "La terre promise, Remember! : l'odyssée carnavalesque de Noël Audet», 1, p. 83-97.

AUDET, Noël, «Inédit. La barbière», 1, p. $25-44$.

BIRON, Michel, «Sortir de la littêrature», 1, p. 166-170; «Le symbolisme soft», 2, p. 167-173; «Il a plu hier», 3, p. 145-153.

BONENFANT, Luc, «Le Nigog: la pratique polémique du poème en prose», 2, p. 125137.

BOURASSA, Lucie, "Économie, résistance et prodigalité», 3, p. 69-82.

BROCHU, André, «Un génie maladroit», 1, p. 171-174; «Ici, c'est ailleurs», 2, p. 179184; «Les voix de l'intime», 3, p. 153-158.

\section{BROUILLETTE, Marc André,}

«Prêsentation», 3, p. 9-11; «De l'espace de la langue à l'espace du poème», 3, p. 44-55.

CARON, Pascal, «L'hiver de force de Réjean Ducharme: les enjeux d'une adaptation thêâtrale», 1, p. 113-125.
CARON, Valérie, «Le bruit des choses vivantes et Tableaux: voix et reprêsentations inédites de la maternité dans la littérature québécoise», 1, p. 126141

\section{CHASSAY, Jean-François et Katherine} ROBERTS, «Présentation», 2, p. 9-12; «Entretien avec Monique LaRue», 2, p. 1329.

CYR, Gilles, «Inédit. Poèmes», 3, p. 12-19.

DION, Robert, «L'instinct du réel: fuites et retours dans Les faux fuyants, Copies conformes et La démarche du crabe de Monique LaRue», 2, p. 30-45; “Identités», 2, p. 197-203.

DOS REIS, Vêra Lucia, «Clês du mensonge, copies de la vérité dans Copies conformes de Monique LaRue», 2, p. 61-72.

DUMONT, François et Marc André BROUILLETTE, «"Accueillir l'inconnu”. Entretien avec Gilles Cyr», 3, p. 20-30.

DUMONT, François, «L'arpenteur et le navigateur: les ambiguïtés d'un essai romanesque», 2, p. 98-108.
FORTIER, Frances, «Vitalitês romanesques ou les traditions réinventées», 2, p. 174179.

FRANCIS, Cécilia W., «L'autofiction de France Daigle. Identité, perception visuelle et réinvention de soi», 3, p. 114-138.

GIGUÈRE, Andrée-Anne et Marc André BROUILLETTE, «Bibliographie de Gilles Cyr», 3, p. 83-92.

HÉBERT, François, "Le "pain qui brille" », 3, p. 56-68.

IRELAND, Susan, «La maternitê et la modernité dans les romans de Monique LaRue», 2, p. 46-60.

JOUBERT, Lucie, «La gloire de Cassiodore: une affaire de genres», 2, p. 86-97; «Telles mères, telles filles?", 3, p. 170-174.

LABBÉ, Luc, «Bibliographie de Noël Audet», 1, p. 98-110.

LANDRY, Gabriel, «Le poète et sa planète», 2, p. 185-191; «Entorses et entortillement», 3, p. 158-162.

LE GRAND, Eva, «Présentation», 1, p. 911 ; «Écriture de la fiction du monde. 
Entretien avec Noël Audet», 1, p. 12-24

«Rêver l'Amérique: pour une lecture de

Frontières ou Tableaux d'Amérique de Noël

Audet», 1, p. 71-82.

LEMIEUX, Marie-Hêlène, «Pour une

sociocritique du roman Kamouraska d'Anne

Hébert", 3, p. 95-113.

NANTEL, Mylène, «Des mots à l'image:

l'adaptation têlêvisuelle de L'ombre de

l'épervier de Noël Audet», 1, p. 60-70.

PAQUIN, Jacques, «Variations sur la pente du langage: le poème comme simulacre du raisonnement scientifique», 3, p. 31-43.
PARÉ, François, «Théories du chaos et de l'anarchie», 1, p. 161-166; «Assumer le risque de l'infidêlitê»», 2, p. 163-167;

«Détresse du fragment», 3, p. 141-145.

PELLAND, Johanne, «La figure du changement dans quatre romans de la Révolution tranquille», 1, p. 142-157.

PLEAU, Jean-Christian, "Polêmique sur un "mauvais livre": L'appel de la race de Lionel Groulx», 2, p. 138-159.

RAYMOND, Richard, «Bibliographie de Monique LaRue», 2, p. 109-122.
ROBERT, Lucie, "Sur la route», 1, p. 174181 ; «Les passeurs de récit», 3, p. 163-170

SAINT-MARTIN, Lori, "Avant-propos», 1, p. 5-6; «Avant-propos», 2, p. 5; «Inventer la mêmoire», 2, p. 191-197; "Avantpropos», 3, p. 5.

SUHONEN, Katri, "Avancer à reculons: une nouvelle trajectoire pour l'identité masculine dans La dêmarche du crabe de Monique LaRue», 2, p. 73-85.

WALL, Anthony, «Le Québec et le far-ouest canadien", 1, p. 182-187. 